\title{
The Historical Development of the Costs of Nuclear Power
}

\author{
Reinhard Haas, Stephen Thomas, and Amela Ajanovic ${ }^{1}$
}

\section{Abstract}

One of the major historical arguments of the promoters of the use of nuclear power was its low cost compared to other electricity generation technologies. For a long time, it was argued that a strong nuclear power contribution to electricity supplies was the best way to achieve a reliable and affordable electricity supply. However, from the first wave of nuclear reactors deployed, construction costs have been on an escalation course.

The core objective of this paper is to analyze the historical development of the costs - especially the investment costs - of nuclear power plants. With respect to these in recent years in Western countries there is a strong perception: Realized costs has always been higher than forecast costs and construction times promised have almost never been met. Given the reasons identified for these cost increases - and their irreversibility - we conclude that the time of "cheap" electricity from nuclear power is undoubtedly over if it has ever existed and for the next years there are no signs of a reversal of the current upward cost trend.

1 Reinhard Haas, Technische Universität Wien, Austria, haas@eeg.tuwien.ac.at; Stephen Thomas, University of Greenwich, United Kingdom, stephen.thomas@greenwich. ac.uk; Amela Ajanovic, Technische Universität Wien, Austria, ajanovic@eeg.tuwien.ac.at

(C) The Author(s) 2019

R. Haas et al. (Eds.), The Technological and Economic Future

of Nuclear Power, Energiepolitik und Klimaschutz. Energy Policy 


\section{Introduction}

One of the major historical arguments of the promoters of the use of nuclear power was its low costs compared to other electricity generation technologies. For a long time, it was argued that it is impossible to retain a secure and affordable and lowcost electricity supply without nuclear power. However, it has to be debated whether that argument was ever valid and from the first wave of nuclear reactors deployed, construction costs have been on an escalation course.

Looking back to the economic promises of the "nuclear dream" of the $1950 \mathrm{~s}$ and 1960s, these focused on very cheap electricity to be provided by nuclear power plants (NPP), electricity even "too cheap to meter" (Lewis Strauss ${ }^{2}$, Cohn, 2007). This idea was based on the rather low investment costs and short construction times (4-6 years) in the early days of the civilian use of nuclear power. Indeed, at this time NPP generated electricity at costs as low as $2-3$ cents $_{2010}{ }^{3}$ per kWh (Cohn, 2007). ${ }^{4}$

Yet, over time the costs of nuclear, especially the investment costs, have increased continuously. In recent decades the high and still increasing costs of nuclear power have become a key barrier to the construction of new reactors around the world. It is clear that in the long run nuclear power will only succeed if its generation costs are lower than those of competing technologies (MIT 2003). This is especially true as electricity systems become increasingly exposed to competitive markets in many parts of the world.

The core objective of this paper is to analyze the historical development of the costs - especially the construction costs - of nuclear power plants. Specific derived objectives are to analyze (i) why the investment costs have increased, (ii) why the construction times have increased, (iii) why the construction costs as well as the construction times have been underestimated systematically, and (iv) whether the reasons for construction cost and time increases are irreversible.

In this context it is important to note that there is a difference between actual investment costs and so-called overnight costs (ONC). The major difference is that the investment costs include also the costs for interest and represent the whole capital costs while the ONC represent the expenses for the technology and construction work only (incl. labor and material cost). Overnight costs are useful for analytical

2 Reference to the full text of what Lewis Strauss said: https://public-blog.nrc-gateway. gov/2016/06/03/too-cheap-to-meter-a-history-of-the-phrase/

3 This means value in terms of money of 2010

4 One could argue strongly whether there was ever an era of cheap nuclear power. The perception of cheapness was based either on cost forecasts that were not fulfilled or on a perception that costs would come down over time and make nuclear power cheap. 
purposes especially for international comparisons because the interest rate is project and country specific but consumers pay the cost including the interest. The European Commission estimated that Hinkley would cost in total $£ 24$.5bn when the overnight cost was estimated at $£ 16 \mathrm{bn}^{5}$.

Of absolutely core interest is why the investment costs increased by such high rates. So far, there is no sound and comprehensive analytical evidence that explains the skyrocketing of the real costs that have occurred since the beginning of nuclear power. An obvious component referred to above but in little clarity is the longer construction times, leading to ever higher interest accrued and to "natural“ cost escalation" of labor and equipment The automatic intuitive assumption is that these extra costs arise from the additional safety requirements resulting from accidents at Browns Ferry, Three Miles Island and Chernobyl. There might also be a need for better quality materials, for example Westinghouse steam generators of the 1970s used a material that corroded too quickly. The reason why the vendors used cheaper material was because costs were too high. This proved a false economy. If raw materials like steel and concrete have gone up faster in real terms than inflation, that would also have increased real costs. Another factor is that reactors seem to have become more prone to cost escalation from the pre-construction forecast, again no analysis to back this up. This raises the issue whether construction costs have gone up because real costs have gone up or because things have gone wrong without the intrinsic cost going up, e.g. how far is the higher than estimated cost of OLK-3 due to the forecast being an underestimate and how far because things have gone wrong, including increases in construction duration.

Another issue is initial price dumping by construction companies. The question would be whether the pre-construction costs have become more realistic again appearing to raise the real cost. Certainly the prices quoted in the 1960s were horrible underestimates (e.g. the 12 US turnkey plants). One problem with pre-construction cost estimates is that unless the vendor gives a fixed price contract (turnkey) and no vendor in its right mind would give a genuinely fixed price contract, the vendors know they can't be held to the pre-construction estimate so they have an incentive to underestimate to get the business.

Other possible reasons for the construction cost increases could be:

- increase in interest rates for financing and an increase in construction duration (which influences the interest costs but not the ONC);

5 See the state aid case verdict 
- changes in design generation ${ }^{6}$, and changes in the engineering design see Grubler (2014), other than extra safety costs covered above.

In addition, in the past it could be suspected that high subsidies such as public subsidies, financial subsidies (low interest rates that did not reflect the economic risk) and government subsidies to industry could have led to much lower costs than have actually been true (Cohn (1997)). Another reason for present day construction cost increases would be that the pre-construction costs have become more realistic thereby appearing to raise the real cost. Certainly, the prices quoted in the $1960 \mathrm{~s}$ were dramatic underestimates. After the experience of vendors facing heavy losses with the 12 US 'turnkey' projects of the mid-60s, vendors were only willing to sign 'cost-plus' contracts so there were no direct financial consequences to them when costs overran. Utilities, in turn, were generally able to pass on whatever costs were incurred to consumers. So neither the vendor nor the buyer generally had to bear the additional costs, they fell on consumers.

So far, studies conducted on the costs and economics of nuclear have focused mainly on the analysis of single plants and cohorts of NPP. In this work we take the results of other studies, add own analyses, e.g. on OLK3, FLA3 and the UK's Hinkley Point $\mathrm{C}$ project (HPC) and derive major findings. To the best of our knowledge so far, no such a systematic analysis of cost developments has yet been conducted.

Regarding the literature on costs and economics the following work is most relevant. The very first studies on cost analyses were already conducted at the end of the 1970s by Tybout (1975), Mooz (1978), Mooz (1979), Mooz (1982) and Komanoff (1981). They already provide very early, sound analyses on the reasons for cost increases and an early outlook on what is looming today, which is that nuclear power will not become a cheap power source at any time.

Cohn (1997) provides a comprehensive corresponding analysis including cost analyses. He explains from a philosophical and economic point-of-view why the nuclear dream has failed to come true. Cohn is the first to describe, why nuclear costs were systematically underestimated, what were the economic problems already in the early years of nuclear and how the word "market" was systematically misused by the major utilities and vendor companies. This work also provides an interesting summary on nuclear spending and costs of NPP in the early days 1955 to 1969 in the US. He showed that these were financed almost completely by the utilities with the incentive to gain know-how. He also documents that even at that time it was generally expected to have higher generating costs than available fossil fuel alternatives and was undertaken as a technology-promoting investment.

6 See Reinberger et al. in this book explaining the change in generations of nuclear 
Another major contribution of Cohn's work is that he was the first to provide a critical discussion on the issue of subsidies and cost deferments. He documents in detail for the time-period from 1950 to 1979 direct expenditure (incl. R\&D outlays, uranium supply and enrichment subsidies, and regulatory subsidies) and implicit subsidies (e.g. tax exemptions and tax benefits) as well as the cost deferments due to e.g. neglecting nuclear waste disposal charges (see Cohn 1997, p.79 for more details).

MIT (2003) conducted a sensitivity analysis and showed under which conditions NPP could become competitive again.

The issue of pre-announced construction costs and actual ones was already discussed by Koomey/Hultman (2007). They present a reactor-by reactor analysis of historical busbar costs for 99 nuclear reactors in the US and compare those costs with recent (2007) projections for next-generation US reactors. Their analysis suggests that projections of capital costs, construction duration, and total operation and maintenance costs are quite low - far away from the historical medians and that additional scrutiny may be required to justify using such estimates in current policy discussions and planning.

Grubler (2010) provides a seminal contribution and a very comprehensive analysis on the developments in France. Grubler's major point of criticism is that lack of standardization and new engineering approaches have avoided the learning and standardization effect. He points out that it is worth saying that France is widely, but wrongly seen as having a fully standardised programme. Actually its 58 reactors are spread over at least 3 main designs (900MW, 1300MW, 1450MW) and 7 variants. Hence, many of the plants used a new untested design.. The scope for learning was restricted because the new variants were ordered before there was any operating experience with their predecessors. There was no conscious decision by France not to standardize, design changes were required because of experience elsewhere, e.g. the need to learn lessons from the Three Mile Island disaster and the need to improve the economics, e.g. by scaling up.

Harris et al. (2012) provide cost estimates for nuclear power in the UK. Their motivation is to analyze the actual cost developments in Europe and derive major conclusions for the future of investment costs in the UK: The primary finding of this paper is that the capital cost for an NPP may be higher than recent UK government reports have indicated and may therefore require greater levels of financial support than policymakers might have originally envisaged. As Harris et al. (2012) state further, due to the significant uncertainties that surround cost estimates for NPP in general it is very difficult to give a high level of confidence to levelised cost estimates.

Rothwell (2015) discusses the basics of economics of nuclear power. Lovering et al. (2016) present an overview on overnight costs (ONC) of $58 \%$ of the nuclear reactors 
world-wide. Koomey et al. (2017) heavily criticize the work by Lovering et al. (2016) claiming that they cherry pick data and include misleading data on early reactors.

This work is organized as follows. In the next chapter we look at the basic cost structure of NPP. Then we analyze the development of investment costs. A specific focus is dedicated to the development of Technological Learning (TL). We discuss why it took place for different technologies for electricity generation but apparently not for NPP. Finally, we argue why the argument that nuclear electricity is cheap is not valid. We explain and show the wrong predictions regarding investment costs and how construction times look like for some recent projects. A summary of the major reasons for investment costs increases of NPP and conclusions complete this chapter.

\section{The cost structure of nuclear power plants}

In principle the cost structure of every power plant consists of investment costs, fuel costs and O\&M costs. In addition, for nuclear plants, significant costs for decommission and backend activities have to be considered, see Irrek (2018) and Wealer et al. (2018) in this book. The specific cost structure of nuclear plants is shown in Fig. 1. Specific features are:

- A very high share of capital costs

- High turnkey costs, actually the highest among all types of power plants

- An (unknown) share of decommissioning costs

Figure 1 shows that the largest amount of the costs - about $80 \%$ - are capital costs resulting from initial investments. In 2004 the IAEA estimated $60 \%$ construction costs, today the share is likely to be even higher because constructions have escalated faster than the other elements. Harris (2012) estimate $80 \%$ share of capital costs and also according to Rangel et al. (2013) NPP competitiveness depends on its capital costs representing on average $80 \%$ of the levelized cost of electricity. However, from the first wave of nuclear reactors construction costs have been on an escalation course and the share of capital costs in total cost increased.

One might ask whether the cost components in Figure 1 are complete and whether all important components are included. Schneider (2006) suggests it is not, stating "The total costs of a nuclear kWh most likely will never be known. Costs for waste management, decommissioning and clean-up are constantly on the rise and are generally expected to be paid by the taxpayer." 


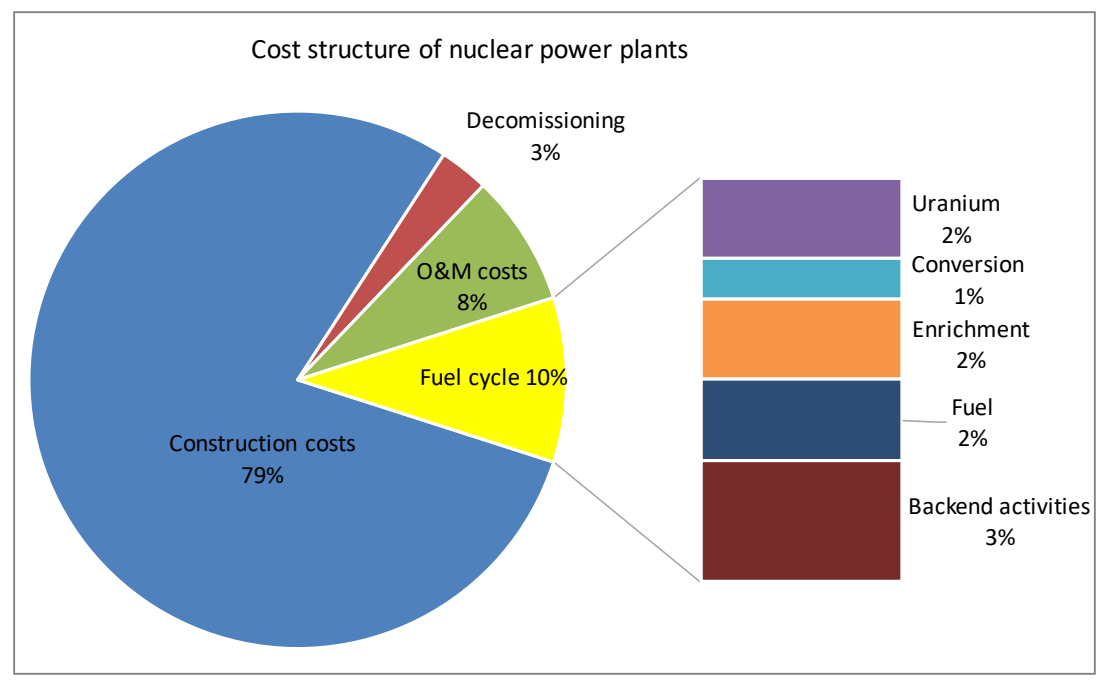

Fig. 1 Typical nuclear electricity generation cost breakdown (based on IAEA (2004) and other sources)

\section{The historical development of investment costs}

As seen from Fig. 1 investment costs contribute the largest share to the electricity generation costs of NPP. In this chapter we put special focus on the analysis of the historical development of investment costs. We provide a dynamic comparison of the investment costs extracted from different studies, with an emphasis on the explanations for reasons for their increase.

The rising investment cost of building nuclear reactors is a well-established fact. It has been studied in detail for installed capacity in the USA and France. However, sound explanations for these cost increases are difficult to find.

The key literature on investment costs is presented below. The first comprehensive analysis of these was conducted by Koomey (2007). Cohn (1997) describes the development of utilities nuclear investments in the U.S. from the 1950s to the 1970s. He states that utilities nuclear spendings/investments can be divided into four clusters (1) the first investor-owned utilities financed and owned projects (1955-1963); (2) the three rounds of the AEC's Power reactor demonstration program (1955-1963); (3) the turnkey years (12/63-1966); and (4) the bandwagon market (1966-1969). An- 
other important work was done by Harding (2007), who analyzed about 60 plants in the U.S. with respect to their investment costs. His findings show that a rapid growth in investment costs took place already over the period from 1955 to 1995.

For the USA the overnight construction costs (ONC) of the first reactors built in the early 1970 s was about $\$ 1000_{2008}$ per $\mathrm{kW}$. It has increased steadily ever since reaching $\$ 5000_{2008}$ per $\mathrm{kW}$ for the recent reactors built in the early 1990s (Rangel et al. 2013). In other words, a one-to-five ratio in constant USD. The increase in the overall construction costs is even more striking. The average construction duration has increased with time, so interest during construction has increased too. The time taken to build an NPP has risen from between four and six years for the first plants to more than twice as long for the most recent units.

With respect to investment costs an important aspect is the difference between so-called ONC and actual investment costs. It is important to note, that there is a fundamental difference between ONC and the net present value (NPV) of the investment costs, the major difference being that the overnight costs do not include the interest costs of financing depending on the plant construction time. As already said the plant construction time does not in itself increase costs other than the interest costs, although if delays reflect difficulties in construction, these might also increase costs.

Of specific relevance in this context is interest during construction (IDC). During the $80 \mathrm{~s}$, there were big battles in the USA between regulators and utilities with utilities trying to get consumers to pay IDC before the plant was on line. Mostly the regulators (rightly) did not give in. US regulation should require utilities to build facilities and only when the facility is complete and the regulator has applied the test of 'used, useful and costs prudently incurred' should the utility be allowed to start to recover its costs from consumers. If a utility fails the test, some or all of the money spent by the utility should not be included in the regulatory asset base and these costs must come out of profits. It was regulators applying this test and threatening to disallow costs that stopped nuclear ordering in its tracks in the USA in 1979 (and led to the cancellation of 100+ orders placed after 1974). So, from an economics point of view this was very important. Without the guarantee of cost pass-through, the banks, credit rating agencies etc made it clear to utilities that building a nuclear plant would be potentially ruinous.

For the financial institutions, delays in construction times and corresponding increases in interest payments play a major role. In addition, almost all modern reactor programs analyzed in detail to date have experienced significantly lengthened construction times particularly in the USA and Europe. Use only of overnight construction costs e.g. by Lovering et al., 2016 means that some of the financial consequences of construction delays is ignored. 
ONC has been used in the utility industry for decades (Koomey et al., 2017, EPRI, 1993; Rothwell, 2015), and they attempt to show a cost that is "meant to isolate the cost invariant to construction duration (Koomey et al., 2017) and interest rate, in order to capture the cost intrinsic to the reactor technology", as Lovering et al., 2016 put it. Despite the use of the term "overnight costs" having a long history, there is simply no economic basis for comparing the costs of reactors without including the cost of capital and the construction duration. However, it is not invalid to look at overnight costs. The argument is that adding in interest costs muddies the picture because you don't know if costs have gone up because interest has increased or because the underlying construction cost has gone up.

A key aspect of nuclear reactors that makes them such high-risk investments are that they are large scale, complex, and pre- dominantly site-built. Hence construction takes years (even in the best case) and can extend over a decade or more (Koomey et al., 2017).

Given that financing constitutes a significant part of the electricity generation costs of an NPP, and that the very nature of nuclear power as a large scale, capital-intensive technology makes it particularly sensitive to financial risks, a study that does not take account of interest during construction cannot give a true picture of the costs of nuclear power.

Another major historical analysis on the development of investment costs of NPP has been conducted by Grübler (2010). He investigated all 58 of the French plants in service in 2018 based on an analysis of costs presented in annual reports by the French government. Of specific interest is Civaux in France a N4 type reactor with extremely high costs. However, regarding the four N4 plants (two each at Civaux and Chooz in France) there were clearly design issues that delayed them. They might have been part of the trend but without these plants the trend is still there. There was a trend of cost escalation amongst the other 54 that did not have these design issue problems. For the French case the cost assessment done by Grubler (2010) pointed out that the units completed after 1990 were 3.5 times more costly than the reactors installed in the 1970s. This finding led to the conclusion that cost escalation was inherent to reactors, given that even under the best conditions, as prevailing in France the construction costs have also risen significantly. These favourable factors included more standardization than was achieved elsewhere, predictable series production allowing efficient production line methods to be used to manufacture parts and learning was concentrated in only one reactor vendor and one utility, which also managed the construction process.

Grubler's analysis was a seminal contribution because it led to the publication of the actual costs of the French nuclear power plants by plant. The so-called negative learning found by Grubler for the French case was shocking and led to discussion 
of this concept. However, the term "negative learning" may lead the reader to think too narrowly. We are skeptical that lost skills account for much of the increased cost and rather think that it is much more about increased scope of the plants, greater complexity which makes the power plants more difficult to build.

Rangel et al. (2013) revisited the French nuclear experience using the actual construction costs of the French nuclear fleet that had been published in a report by Cour de Comptes and they found positive learning effects when building the same type of reactors as a result of Grubler's work. With this information they have tried to identify investment costs' main drivers and found some lessons to explain the cost escalation phenomena. Regarding 'same type of reactors' it is important to state that there were 4 different, tranches' of 900MW reactors, Programme 1970 (6 reactors), CP900-1 (16), CP900-2 (8), Tranches 900 (4). And there was CP-1300-1 (20) and N4 (4), Thomas (1987).

They stated the importance of recognizing that the centralized nature of the French NPP programme not only allowed a fast deployment of this technology but also shielded its costs from private eyes and public scrutiny. As argued by Rangel et al. (2013) the cost escalation with the Cour de Comptes (CdC) data was less severe. On the basis of the analysis of the Cour de Comptes report there would be reason to believe that the construction cost escalation in France is mainly due to the increase in the labor costs but also due to the scaling-up strategy. No economies-of-scale were observed, rather diseconomies of scale. However, Grubler (2014) argues that the $\mathrm{CdC}$ data are heavily biased and omit arbitrily important construction costs components. He compares his estimates with CdC (corrected for omissions) criticizes that Rangel and Leveque (2013) have compared the lowest CdC numbers (73 billion) to the best-guess model estimates 89 billion reported in Grubler (2010), and that Rangel et al. (2013) reached the pre-mature conclusion of a significant overestimation of costs and resulting cost escalation of the Grubler costing model. The low end of the range uses the CdC's original estimate excluding construction engineering and labour costs, and considers the Tricastin 3,4 versus the Chooz 1,2 reactor costs as reported in CdC 2012: 22-23; the high end of the range uses the $\mathrm{CdC}$ costs adjusted to include construction engineering and labour, plus the 13 to 23 billion Euro2010 accrued interest during construction

Another specific phenomenon is the issue of economies-of-scale. It has generally been assumed that nuclear power plants would be amenable to scale economies. The bigger the cheaper was a basic approach. However, there has not appeared any empirical evidence to prove this assumption. On the contrary, studies from the 1970 s showed no evidence of scale economies. E.g Cantor/Hewlett (1988) calculated that a $1 \%$ increase in the size of a reactor resulted in a $0.13 \%$ rise in the ONC per $\mathrm{kW}$. Following Leveque (2015), for France the increase in the reactor size was accompa- 
nied by greater complexity and lead-times which in turn led to higher investment costs per MW. How far this greater complexity was the result of increased scale and how far it was due to the larger reactors being more recent and therefore requiring additional safety systems, for example to take account of Three Mile Island, is difficult to determine. In addition, a key potential influence is so-called economies of number, ie the more per year you make of a particular item, e.g. a unit of a power plant (same size) the cheaper the production is because the fixed costs of production lines is spread more thinly and more efficient production methods can be used.

In 2016 Lovering et al. conducted an analysis on the ONC of $58 \%$ of the nuclear reactors world-wide. In that article the authors purport to show that using this larger dataset yields more representative results than analyses that focus on individual countries explicitly citing Koomey et al. (2007) for the United States and Grübler (2010) for France as examples of country-level treatments. This work was heavily critiziced by Koomey et al. (2017). Koomey et al. argue that construction duration and interest payments are integral parts of the overall construction costs. Another issue with the work by Lovering (2016) raised by Koomey et al. was the reliability of the data they added. They included reactors of several designs, eg heavy water reactors (HWRs) going back a long way to prototype and demo plants and from countries like India, Korea, China where there must be doubts about the reliability of the data.

The big picture with respect to a comparison of major studies on the historical development of investment costs of nuclear power plants is provided in Fig. 2. It provides a descriptive analysis of data of different studies and single plants. As seen over time a considerable uptake took place. An important aspect is that for OLK3 and FLA 3 initially much lower costs were expected than reported before e.g. by Grubler (2010) for France in 2000. The latest data suggest that the ONC for Olkiluoto 3 will be about $€ 8 \mathrm{bn}$, the latest estimate for Flamanville is $€ 10.9 \mathrm{bn}$. ${ }^{7}$ These are plants where almost everything possible to go wrong has gone wrong yet they are cheaper than Hinkley Point C (HPC) which is only expected to start construction between 2019-21 and whose latest cost estimate is $£ 9.8-10$.15bn per reactor or about $€ 12 \mathrm{bn}$. Is that because HPC is really more expensive than FLA3 or OLK 3 or because the HPC estimate is so padded to prevent cost escalation falling on the owner?

7 https://uk.reuters.com/article/us-edf-flamanville/edfs-flamanville-reactor-start-againdelayed-to-2020-idUKKBN1KF0VN (Accessed August 22, 2018) 


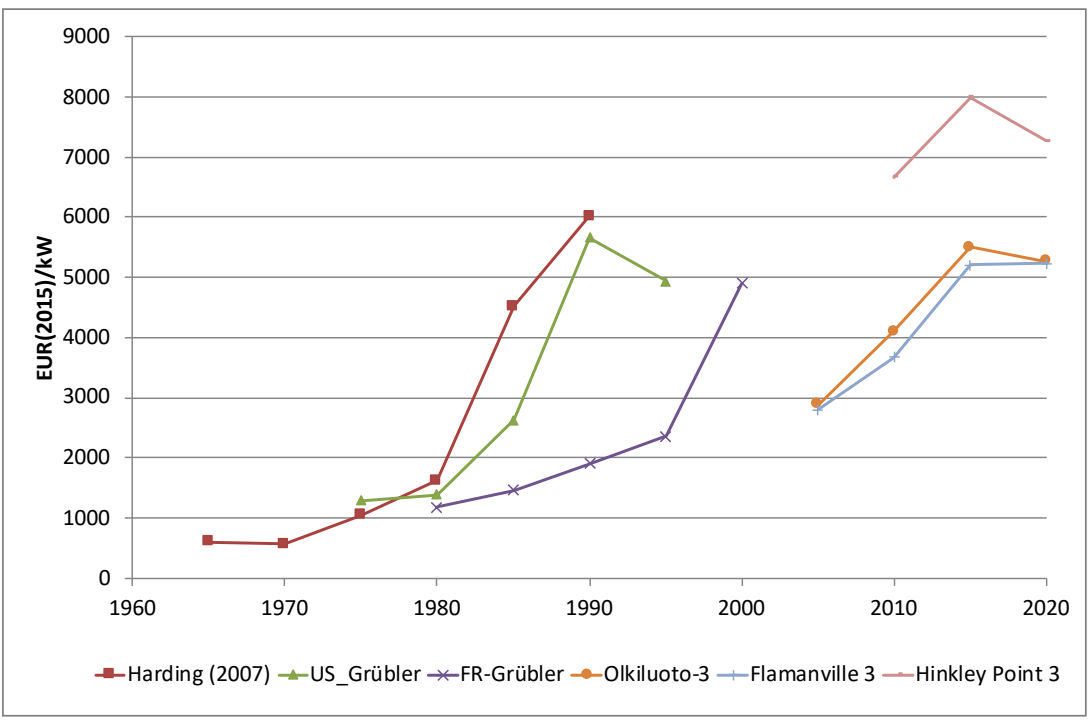

Fig. 2 The big picture: A comparison of major studies on the historical development of investment costs of nuclear power plants

It is important to state that Hinkley Point is unusual amongst nuclear projects because the investment costs and total cost are in advance set relatively high. It is the first time, that the investment costs of a NPP are in advance estimated to be on a higher level than all NPP constructed so far (or under construction).

\section{$4 \quad$ Technological Learning}

The next issue we discuss is Technological Learning. It goes in principle along with the dynamic development of investment costs of any technology. The idea is that it is well known that the cost of a technology is expected to drop as it is deployed more widely. That is to say, it is of interest to identify whether with increasing capacities deployed a decrease in investment costs took place. Some major references is in this context are Wene (2000), McDonald/Schrattenholzer (2001), Kobos (2006), Wiesenthal et al. (2010). On learning, one has to be careful. The original Arrow definition (Arrow 1962) was very narrow and encompassed better performance 
using the same capital stock. In short the workers simply got better at using the equipment. This may be too narrow but it is probably useful to distinguish between design changes that arose because technical change/progress allowed new options to be pursued and design changes that resulted from experience with existing designs.

Nuclear technology displays the opposite trend to reductions in cost. We think that there are four factors that would lead to lower costs for a normal successful technology: economies of scale, economies of number, learning by doing and technical progress. Actually, we are convinced that learning has taken place, but it either hasn't reduced costs or other factors have swamped learning cost reductions. For example, the experience at Three Mile Island was certainly learning but it increased costs. We think it is important to really distinguish and accurately separate these effects which are quite distinct. Of course, this is not easy. A key phrase may be 'a successful technology'. It might be that technologies that do not have scope for these effects fail for that reason. The problem with nuclear is that it was not allowed to fail. In addition, as Leveque states, all other things being equal, the more powerful the reactor, the smaller the number of identical units built.

With respect to Technological Learning for NPP the following is important: Even in the times of booming plant construction in the 1970s and the 1980s nuclear was one of the few exceptions in the sense that additional capacities constructed did not lead to resulting cost reductions. They are mainly that for the early plants no real costs were revealed. Costs were distorted by public subsidies, subsidies from industry (from the constructors of plant to get into the market) and of financing subsides due to very favourable interest rates. Over the course of time these subsidies were gradually removed and costs increased instead of following the classical learning theory. In addition, it is worth mentioning that learning could increase costs, e.g. if a cheap material is not good enough, or existing designs are not safe enough.

\section{$5 \quad$ Historical developments of construction times}

One major reason for the increases in nuclear generation costs is the increase of construction times. As an example Grubler (2010) analyzed the historical development of construction times of nuclear power plants in France between 1965 and 2005. His results show that up to 1985 the majority of construction times were between 60 and 84 months. After 1985 the average duration increased in a virtually linear way. In this view for France also the first announcement for the construction time of FLA-3 was included. It is by no means clear what was the intention beyond this cost announcement and the corresponding construction time of five years (see 
later) because the construction times for the plants built in the years before were already significantly higher, twice as high and more. Obviously, the intention was to convince decision makers that FLA-3 would be economic. The forecast cost $(€ 3.2 \mathrm{bn})$ and construction time (five years) for Flamanville were significantly lower than the most recent experience but more realistic figures would have made the project hard to justify. Fig. 3 shows the increase in estimated construction times for five typical cases world-wide. The graph should be read as follows: On the vertical axis are the construction times indicated in months. The lines show how they increased or remained stable over time. E.g. for OLK-3 in 2004 the estimate for the construction time was 60 months in 2018 it is 200 months (Source: Platts, Power in Europe, various issues).

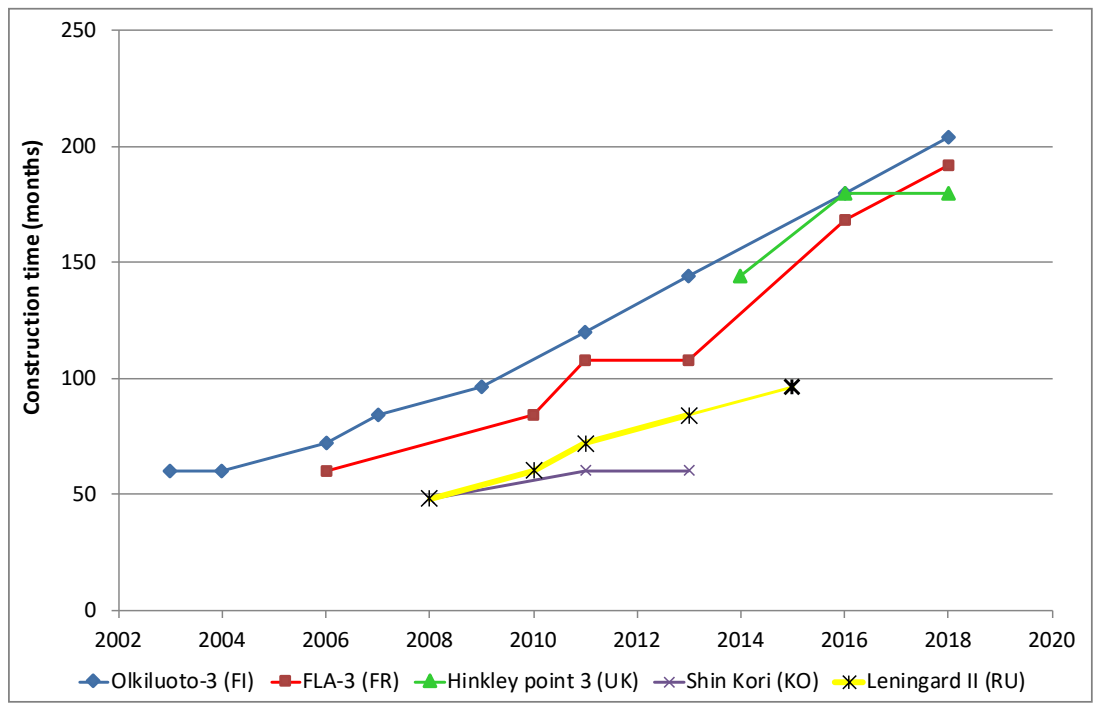

Fig. 3 Increase in the delays of construction times for five typical cases world-wide 


\section{Lessons learned from the developments of Flamanville and Olkiluoto}

Another major question is what caused the increase in construction duration of the NPPs in Finland, France and the US still under the construction. In addition, there was an increase in construction times in China and Russia for China from 2011 onwards and for Russia with the latest design. For instance, the construction of the first European pressurized reactor (EPR) in FLA3 in France revealed that even when this reactor was initially thought as no more costly than its predecessor (the N4) this would not be the case.

At the beginning of 2005 the estimated cost of this project were $€ 3.2$ billion. However this figure was revised in 2011, when the state-owned French company Electricite-de-France (EdF) announced that the costs had reached $€ 6$ billion. This situation even worsened with the latest press releases stating $€ 8.5$ billion in 2012 and 9.5 billion in 2016. The latest estimate is $€ 10.9 \mathrm{bn}$ (Platts, 2018).

For the Westinghouse latest design (AP1000) the situation for the two pairs of reactors (Summer and Vogtle) that started construction in the US is very similar. The first cost estimates done both in 2003 were around USD 2400/kW. These costs were later revised stating ONC in USD 2010 of $5100 / \mathrm{kW}$. The pattern is that all three Gen III+ designs that have started construction - EPR, AP1000 and AES2006 have overruns of time much longer than their predecessors. In Russia and China, contemporary projects using earlier designs were much less delayed. Because Gen III+ has higher design safety, if this leads to greater complexity and makes them more difficult to build, contrary to the claims made for Gen III+, this will increase their costs and increase lead times which, if it reflects construction problems will also increase interest costs.

\section{Summarizing the major reasons for investment costs increases of NPP}

In the following we summarize the major reasons for investment costs increases of NPP. As stated, so far there is no precise and comprehensive analytical evidence that explains the skyrocketing of the real costs of NPP that have occurred since the beginning of nuclear power use. Our explanations for the major reasons for the cost increases are: 
- The intuitive assumption is that these extra costs arise from the additional safety requirements resulting from accidents at Browns Ferry, Three Miles Island and Chernobyl (and of the 9/11 attack). Indeed, as Rangel (2013) and Leveque (2015) have proven for France increases in safety equipment have contributed to about half of the construction cost increases in France between 1970 and 1990;

- There might also be a need for better quality materials, for example Westinghouse steam generators of the 70s used a material that corroded too quickly. If raw materials like steel and concrete have gone up faster in real terms than inflation, that would also have increased real costs (Cohn 1997, Grübler 2010, Thomas (2005)). Increases in labour and material costs is also argued as a major cost driver by Leveque (2015) for France;

- A systematic underestimation of the construction costs as well as the construction duration: One factor is that reactors seem to have become more prone to cost escalation from the pre-construction forecast. Another reason for present day construction costs increases is that the pre-construction costs have become more realistic thereby appearing to raise the real cost. Certainly, the prices quoted in the 1960s were dramatic underestimates.

- Finally, costs could have gone up because things simply have gone wrong without the intrinsic cost going up, e.g. how far is the higher than estimated cost of OLK3 due to the forecast being an underestimate and how far because things have gone wrong, raising costs. In this context also the question is of interest whether Western companies simply do not have the skills anymore to complete huge projects on time. The next obstacle concerns on-site construction and short production runs. Much like other civil engineering projects - bridges, airports e.g in Berlin - NPP are mainly built on-site.

- However, increases in interest rates for financing has not been identified as a driver by any study.

Other possible reasons for the cost increases are:

- the removal of public and industry subsidies;

- increase in construction times: Western companies have lost skills due to the lack of new orders, and are no longer able to construct plants on time, with huge delays leading to construction times two or three times longer than planned;

- changes in generation, e.g from GEN II to GEN III and changes in the engineering design (reduces possible Learning effects);

- The ending of dumping by construction companies;

- The fact that scaling-up appears to have increased, not decreased costs as illustrated in France (Leveque, 2015). 


\section{Conclusions}

Looking back to the years of the nuclear dream in the 1950s and 1960s one of the major historical arguments by the promoters for generating electricity from nuclear power was its low costs compared to other electricity generation technologies. However, from the first wave of nuclear reactors construction costs have been on an escalation course. To date no systematic analysis on the reasons why the costs - especially the investment costs - of NPP have skyrocketed, has been conducted. This work is the first that presents the major reasons for investment costs increases in a systematic structured way.

The major conclusions of this analysis are: There is one core perception regarding the costs of nuclear power plants in recent years: actual costs have always been higher than stated prior to construction and construction times have always exceeded those promised, in most cases considerably. In addition, Western companies have lost skills, and are even less able to construct plants on time, with huge delays leading to construction times two or even three times longer than planned. For nuclear power plants in Western Europe and the U.S. in the last 40 years it can be stated that (i) forecasts of construction times have never been reliable; (ii) forecasts of investment costs have seldom if ever been fulfilled, actual investment costs were always higher than costs announced; (iii) currently there are no signs anywhere of a cost decrease.

What can be stated today is that the economic performance of new nuclear power plants, particularly in the Western countries, has declined substantially compared to their predecessors and to competing power generation technologies. The costs of nuclear power have increased dramatically while on the other hand the costs of wind and photovoltaics - now the major competitors - have fallen the economic performance of nuclear in comparison to these renewable technologies is getting worse.

It will be become much harder for nuclear to recover money in renewable-based electricity markets - much less base load needed - even the pure operation \& maintenance costs are difficult to recover in today's electricity markets leading to more and more unfavourable future prospects of nuclear from an economic pointof-view (MIT 2003). In addition, the introduction of competition to electricity markets means the financial risks that were previously borne by the customer must now increasingly be borne by the investors. Because of these risks faced in competitive electricity markets, interest rates have risen and "investors tend to favour less capital intensive and more flexible technologies”. Or as an influential interdisciplinary study conducted at the MIT as long ago as 2003 stated "Today, nuclear power is not an economically competitive choice”. In addition, as Leveque 
(2015) states: "unless nuclear industry moves away from the present model of large, non-modular plants and gigantic construction projects, the investment costs of NPP are likely continue to rise."

Given the identified reasons for the cost increases - and their irreversibility - we state that the time of "cheap" electricity from nuclear power is undoubtedly over - regardless, whether it has ever existed - and for the next years there are no signs of a reversal of current upward going cost trends.

\section{References}

Arrow, K., 1962. The Economic Implications of Learning by Doing. Rev. Econ. Stud. 29, 155-173.

Cantor R., Hewlett J., 1988: The economics of nuclear power: Further evidence on learning, economies of scale, and regulatory effects. Resources and Energy, Volume 10, Issue 4, December 1988, Pages 315-335

Cohn, Steven Mark, 1997. Too cheap to meter, State university of New York Press.

EPRI Electric Power Research Institute, 1993. TAG-Technical Assessment Guide:Vol. 1: Electricity Supply-1993. EPRITR-102276-V1R7.

Grubler, Arnulf, 2010. The costs of the French nuclear scale-up:a case of negative learning by doing. Energy Policy. 38, (9), 5174-5188.

Grubler, Arnulf, Wilson, Charles, 2014. Energy Technology Innovation, Learning from Historical Successes and Failures. Cambridge University Press, Cambridge, UK.

Grubler, Arnulf, 2014. The French pressurized water reactor programme. In: Grübler, A., Wilson, C. (Eds.), Energy Technology Innovation, Learning from Historical Successes and Failures. Cambridge University Press, Cambridge,UK, pp. 146-161.

Harris et al (ICEPT), 2012. Cost estimates for nuclear power in the UK. Imperial college center.

Hultman, Nathan E., Koomey, Jonathan G., 2013. Three Mile Island: the driver of US nuclear power's decline? Bull.At.Sci. 69(3), 63-70 http://bos.sagepub.com/ content/69/3/63.abstract.

IAEA, 2004. Nuclear Enery Today. Nuclear Energy Agency.

Komanoff, Charles, 1981. Power plant cost escalation, Van Nostrand Reinhold, New York

Koomey, Jonathan, Hultman, E. Nathan, Grubler Arnulf, 2017. A reply to "Historical construction costs of global nuclear power reactors". Energy Policy 102, 640-643.

Koomey, Jonathan G., Hultman, E. Nathan, 2007. A reactor-level analysis of busbar costs for U.S. nuclear plants,1970-2005. Energy Policy 35 vols. (11), 5630-5642. http://dx.doi. org/10.1016/j.enpol.2007.06.005.

Lévêque, Francois, 2015. The Economics and Uncertainties of Nuclear Power, Cambridge University Press.

Lovering, Jessica R., Yip, Arthur, Nordhaus, Ted, 2016. Historical construction costs of global nuclear power reactors. Energy Policy 91(4), 371-382 http://www. sciencedirect. com/science/article/pii/S0301421516300106. 
Kobos P. H., Jon D. Erickson, Thomas E. Drennen, 2006. Technological learning and renewable energy costs: implications for US renewable energy policy, Energy Policy 34, 1645-1658.

McDonald A., L. Schrattenholzer, 2001. Learning Rates for Energy Technologies, Energy Policy, Vol. 29, No. 4, 255-261.

MIT, 2003. The future of nuclear power, An international MIT study.

Mooz William E., 1978 Cost analysis of light water reactor power plants, Rand Corporation, Santa Monica, CA (1978) R-2304-DOE.

Mooz William E., 1979. A second cost analysis of light water reactor power plants, Rand Corporation, Santa Monica, CA, R-2594-RC.

Mooz William E., 1982. An updated data base for light water reactor power plants, Rand Corporation, Santa Monica, CA, R-1899-RC.

Platts, 2018: Power in Europe, Issue 787 / December 3, 2018.

Rangel L. E., Leveque F, 2013. Revisiting the Nuclear Power Construction costs Escalation Curse, The Energy Forum 3, 14-15, 2013.

Rothwell, Geoffrey, 2015. Economics of Nuclear Power. Routledge, NewYork,NY http:// amzn.to/1RyHfLx.

Schneider, Mycle, 2006. The nuclear endgame.

Thomas, Steve, 2005. The economics of nuclear power, Heinrich Böll Stiftung, Nuclear Issues Paper No. 5.

Thomas, Steve, 1987. The realities of nuclear power' (CUP), Cambridge Energy Studies.

Tybout, Richard, "The Economics of nuclear power”, Am Econ Rev, 47, 2, 359-360.

Wene, Claes-Otto, 2000. Experience Curves for Energy Technology Policy, International Energy Agency, OECD/IEA.

Wiesenthal et al., 2012. Technology Learning Curves for Energy Policy Support, EC Joint research centre.

Open Access This chapter is licensed under the terms of the Creative Commons Attribution 4.0 International License (http://creativecommons.org/licenses/by/4.0/), which permits use, sharing, adaptation, distribution and reproduction in any medium or format, as long as you give appropriate credit to the original author(s) and the source, provide a link to the Creative Commons license and indicate if changes were made.

The images or other third party material in this chapter are included in the chapter's Creative Commons license, unless indicated otherwise in a credit line to the material. If material is not included in the chapter's Creative Commons license and your intended use is not permitted by statutory regulation or exceeds the permitted use, you will need to obtain permission directly from the copyright holder.

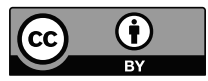

